\title{
XLVI. On essential oil of sage
}

\section{M.M. Pattison Muir F.R.S.E. \& S. Sugiura}

To cite this article: M.M. Pattison Muir F.R.S.E. \& S. Sugiura (1877) XLVI. On essential oil of sage, Philosophical Magazine Series 5, 4:26, 336-348, DOI: 10.1080/14786447708639352

To link to this article: http://dx.doi.org/10.1080/14786447708639352

$$
\text { 曲 Published online: } 13 \text { May } 2009 .
$$

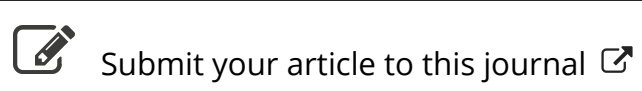

\footnotetext{
Џ Article views: 2
}

Q View related articles $\sqsubset$ 
If the results thus obtained for the five metals silver, platinum, copper, gold, and aluminium be assumed to hold for metals in general, then the results of this investigation may. be summed up as follows:-

In a circuit consisting of two different metals a photoelectric current is generated whenever the two junctions are exposed to luminous radiation of different intensities.

When the same junction is exposed in one case to an increase of temperature and in another to a more intense illumination, the thermoelectric and photoelectric currents respectively generated in these cases are opposed to each other in direction.

XLVI. On Essential Oil of Sage. By M. M. Patrison MuIR, F.R.S.E., Assistant Lecturer on Chemistry, and S. Sugiura, Chemical Student, in The Owens College*.

1. TSSENTIAL oil of sage is obtained by distilling sage 1 (Salvia officinalis) with water. The oil upon which we have worked was procured from Messrs. Wright, Layman, and Umney, of London. It was by them believed to be a genuine specimen. We were unfortunately unable to ascertain the age of the sample.

2. The oil was of a yellowish-brown colour, without any shade of green. The smell was intensely sage-like; the taste was hot and burning; the reaction was neutral. 'I'he oil did not become resinous, nor did it deposit solid matter on standing in a loosely covered vessel for some months; the reaction remained neutral.

The oil readily absorbs oxygen from the air ; about 80 cubic centims. of the sample was allowed to stand in an inverted tube containing air, and placed in sunshine. After two days, the level of the oil in the tube showed that the oxygen (about 4 cubic centims.) contained in the confined air had been entircly removed. On testing the oil with paper soaked in starch-paste and potassium iodide, a blue coloration was produced, but only after some time.

Concentrated nitric acid acts most energetically upon sagcoil, with the production of a red semiresinous body: this action is explosive in its violence if the oil and acid be shaken together.

Strong sulphuric acid causes the production of a brownishred semiviscid mass ; by this action much heat is developed, and sulphur dioxide is evolved. If the semisolid mass be

* Read before the British Pharmaceutical Conference, Glasgow Meeting, 1876; and Plymouth Neeting, 187\%. Communicated by the Authors. 
allowed to remain at rest for twenty-four hours, and water be then added, and the liquid submitted to distillation in a current of steam, a distillate is obtained, the oily portion of which, when separated from the aqueous part and dried, boils for the most part between $215^{\circ}$ and $225^{\circ}$. This distillate appears as a heavy yellow-coloured oil ; it is most probably a polymeride produced by the action of the sulphuric acid upon the hydrocarbons present in the original oil.

The greater portion of the product of the action of strong sulphuric acid upon the oil remains behind, after distillation in steam, in the form of a very thick black resin, which becomes almost solid after standing in the air for some time.

The action of dry hydrochloric acid gas upon sage-oil, maintained at a temperature of $-10^{\circ}$ to $-15^{\circ}$, does not result in the production of any solid chlorhydrate. The product, when distilled, boils chiefly at $195^{\circ}$ to $205^{\circ}$, but contains only from 1 to 2 per cent. of chlorine, with varying quantities of carbon, hydrogen, and oxygen. If a chlorhydrate is originally formed, it readily undergoes decomposition ; the hydrocarbons appear to be partially polymerized by the action of the hydrochloric acid.

A portion of the oil, when mixed with about half its volume of water, the same quantity of strong nitric acid, and one volume of alcohol, became dark red in colour, and after some days separated into an under, light-jellow, and an upper, dark-coloured layer. No solid matter was deposited, however, after twelve months' standing. At the expiry of two months the two layers had reunited.

3. On submitting the oil to distillation, a small quantity of water came over; after the removal of this, distillation began at about $170^{\circ}$; four fifths of the whole quantity of oil distilled between this point and $215^{\circ}$, the greater portion boiling between $175^{\circ}$ and $195^{\circ}$. That portion which boiled below $190^{\circ}$ was treated with sodium, which eaused the formation of considerable quantities of red resinous matter, and again distilled; about four fiftbs of the whole again passed over below $190^{\circ}$, leaving a semisolid red gelatinous mass, which dissolved in ether to form a brown-coloured liquid with a slight green fluorescence.

The fraction boiling at about $190^{\circ}$ deposited a small quantity of solid matter after standing for some time; it was therefore exposed to the cold of several successive days and nights during a rather severe frost, whereby a larger quantity of solid matter was separated.

That fraction, obtained in the first distillation of the oil, which boiled above $190^{\circ}$, was now submitted to fractionation

Phil. Mag. S. 5. Vol. 4. No. 26. Nov. 1877. 
without being treated with sodium. The greater portion came over below $210^{\circ}$. After repeated fractionation and removal of the solid matter which separated out on standing, the main portion of this liquid boiled between $198^{\circ}$ and $203^{\circ}$.

After each fractionation, however, a considerable quantity of resinous matter remained in the flask; and it was only when this had been repeatedly removed that it was found possible to distil the liquid entirely below $203^{\circ}$. It would thus appear that the liquid contained compounds which became polymerized by the action of heat alone; in this respect it agrees with the behaviour noticed in the case of many other essential oils. After repeated distillation over sodium, the fraction which, on the second distillation, boiled below $190^{\circ}$, was split up, for the most part, into two portions:-a smaller, boiling from $156^{\circ}$ to $158^{\circ}$; and a larger, boiling from $166^{\circ}$ to $168^{\circ}$. During the fractionation a very considerable quantity of yellowish-red resin was formed, chiefly, it seemed, by the action of the sodium upon the oil. This resin was decomposed by agitation with water; the oil obtained was separated, dried, and again fractionated. From the fractions of higher boiling-points a large portion of the solid matter already noticed separated on standing at the ordinary temperature.

In the first distillation of the oil, boiling was discontinned upon the temperature reaching $215^{\circ}$; that which remained was a thick, very dark-coloured liquid. This liquid was now submitted to distillation; about one half distilled below $250^{\circ}$, leaving a semisolid, nearly black mass in the retort. On fractionating the distillate, solid matter was deposited from those fractions which boiled below $220^{\circ}$, but not from the higher fractions. After the removal of all matter volatile below $240^{\circ}$ a dark-brown liquid, with distinct gieen fluorescence, remained in the flask. This liquid was subjected to distillation in a current of superheated steam. About ono eighth of the total liquid was obtained in the distillate, the remainder having become almost solid. The distillate, after drying and fractionation, was found to consist almost completely of the solid matter already referred to, held in solution by hydrocarbons.

The oil was thus separated into four main portions :-

(1) A liquid boiling at $156^{\circ}$ to $158^{\circ}$.

(2) A liquid boiling at $166^{\circ}$ to $168^{\circ}$.

(3) A liquid boiling at $198^{\circ}$ to $203^{\circ}$.

(4) A solid deposited chiefly from those fractions of the oil boiling from $190^{\circ}$ to $220^{\circ}$.

The resinous matter which remained after the final distil- 
lation was very probably produced, or at any rate partly produced, by the polymerizing action of heat upon the original constituents of the oil.

4. That portion of the distillate which boiled from $156^{\circ}$ to $158^{\circ}$ was fractionated until the greater portion boiled constantly at $157^{\circ}$ to $157^{\circ} .5$ (thermometer surrounded with vapour, and barometer at 760 millims.). The liquid so obtained was perfectly colourless; it had an exceedingly slight odour of sage.

We have not subjected this liquid to analysis; but the results of a determination of its vapour-density, and a consideration of its general properties, leave no doubt that it really consists of a terpene, $\mathrm{C}_{10} \mathrm{H}_{16}$.

The vapour-density was determined by a slight modification of Hofmann's method, which we have described in a paper communicated to the Chemical Society*. 'The method is easily and quickly carried out, and yields results sufficiently accurate for general purposes.

The following numbers were obtained :-

Height of barometer $=755$ millims.

Temperature of air $=17^{\circ}$.

Height of mercury column in barometer tube $=561$ millims.

Temperature of vapour $=185^{\circ}$.

Tension of mercury vapour at $185^{\circ}=12$ millims.

Weight of mercury required to occupy space formerly occupied by vapour $=1018.4$ grms.

Temperature of mercury $=20^{\circ}$.

Hence, volume of vapour $=73.28$ cubic centims.

Weight of liquid $=0.0682 \mathrm{grm}$.

Weight of volume of hydrogen equal to volume of vapour under same conditions of temperature and pressure $=0 \cdot 00101$ grm.

$$
\text { Hence } \frac{\mathrm{M}}{2}=\frac{\cdot 0682}{\cdot 00101}=67 \cdot 46 \text {. Calculated }=68 \text {. }
$$

5. The specific gravity of this terpene was 0.8635 at $15^{\circ}$.

To Dr. Gladstone we are indebted for determinations of the refractive indices of this terpene. We desire to give our best thanks to him for his great kindness.

$$
\mu \mathrm{A}=1 \cdot 4611 . \quad \mu \mathrm{D}=1 \cdot 4667 . \quad \mu \mathrm{H}=1 \cdot 4855 \text { at } 24^{\circ} .5 \text {. }
$$

Hence specific refractive energy $=0.0534$, and

Refraction-equivalent $=72 \cdot 6$.

6. Dr. Tilden has been so very good as to examine the

* Chem. Soc. Journ. vol. ii. 1877, p. 140. 
action of nitrosyl chloride upon this terpene, and to determine the rotatory power of a column of the liquid. The action of nitrosyl chloride is in every respect similar to that observed between the same substance and the terpene from French turpentine oil *. The nitroso-derivative, $\mathrm{C}_{10} \mathrm{H}_{15} \mathrm{NO}$, forms monoclinic prisms of the same form as those described by Story Maskelyne in an appendix to the paper of Tilden referred to:- "The plane ends are replaced by a sort of pyramid, which makes them look more pointed. In general appearance the crystals are not unlike dog-tooth spart. The melting-point of the nitroso-derivative is $129^{\circ}$; the alcoholic solution of this substance is optically inactive. The specific rotatory power of the sage-terpene is $[\alpha]_{\mathrm{D}}=-37 \cdot 3$.

7. The determinations of the optical properties of this terpene agree rery closely with those which have been made for the terpene from French turpentine-oil (terebenthene). Moreover the specific gravity of the sage-terpene is practically identical with that of terebenthene. Riban $\neq$ gives tho formula $0.8767-0.0008277 t$ as expressing the specific gravity of terebenthene at any temperature, $t$, below $80^{\circ}$. At $15^{\circ}$ thie specific gravity would be 0.8643 . The specific gravity of sageoil terpene is 0.8635 at $15^{\circ}$. The boiling-points of the two terpenes are also almost identical, probably really identical. As we shall show hereafter, the sage-terpene contained a small quantity of cymene, which would tend slightly to decrease the specific gravity, and slightly to increase the boiling-point of the liquid.

In the following Table we have noted some of the physical properties of terebenthene and of the terpene from sage-oil boiling at $157^{\circ}:-$

Sage-terpene. Terebenthene.

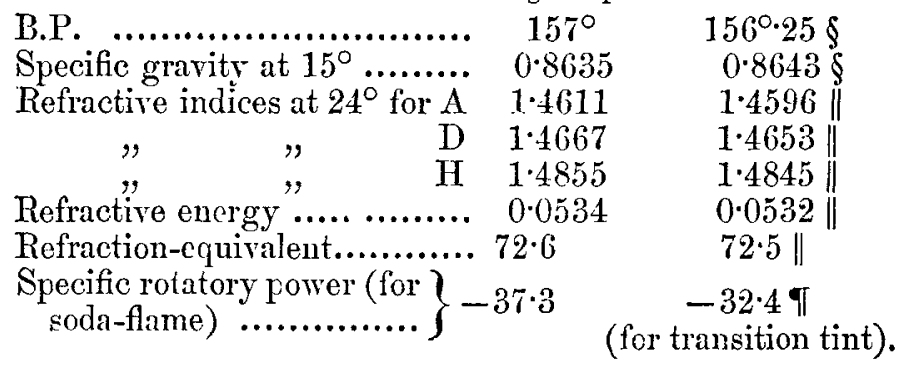

* See Tilden, Chem. Soc. Journ. [2] xiii. p. 514.

+ Extract from letter from Dr. Tilden.

† Comptes Rendus, lxxviii. p. 288.

\$ Riban, Comptes Rendus, lxxriii. p. 288.

I| Gladstone, Phil. Trans. 180?.

It Berthelot, Ann. Chem. Pharm. Ixsxi iii, 313. 
8. About 20 grms. of the terpene boiling at $157^{\circ}$ was surrounded by a freezing-mixture, and concentrated sulphuric acid was added drop by drop, the liquid not being allowed to become warm. A trace of sulphur dioxide was evolved, and a deep-red semisolid mass was formed. After 24 hours this was distilled in a current of steam; the distillate was dried and fractionated; the greater portion boiled between $175^{\circ}$ and $178^{\circ}$, and gave the reactions of cymene. On analysis, the following numbers were obtained :-

0.1885 grm. gave 0.6125 grm. $\mathrm{CO}_{2}$, and 0.181 grm. $\mathrm{H}_{2} \mathrm{O}$.

\begin{tabular}{|c|c|}
\hline & $\begin{array}{c}\text { Calculated for } \mathrm{C}_{10} \mathrm{H}_{14} \text {. } \\
89.55\end{array}$ \\
\hline Hydrogen & ..... $10 \cdot 45$ \\
\hline
\end{tabular}

A small quantity of this cymene was oxidized by chromic liquor; it yielded terephthalic and acetic acids.

About 7 per cent of cymene was obtained from tho terpene.

9. Twelve grms. of the terpene, placed in a flask surrounded with snow and salt, was subjected to the action of bromine, added drop by drop through a narrow tube. The bromine was very rapidly absorbed, a hissing noise being produced on the addition of each drop. When no further absorption appeared to take place, it was found that the liquid weighed 25 grms. In order to convert 12 grms. of $\mathrm{C}_{10} \mathrm{H}_{16}$ into $\mathrm{C}_{10} \mathrm{H}_{16} \mathrm{Br}_{2}, 14$ grms. of bromine (in round numbers) aro required; 13 grms. were used in the foregoing experiment. The liquid thus obtained was a heavy colourless oil. On submitting it to distillation, torrents of hydrobromic acid were evolved, and a nearly colourless liquid came over, which, however, quickly darkened, until of a reddish-brown colour. On attempting to distil this liquid, it was again decomposed, vielding hydrobromic acid, a distillate boiling from $175^{\circ}$ to $180^{\circ}$, another and heavier portion boiling from $220^{\circ}$ to $240^{\circ}$, and a considerable quantity of black resin. This process was repeated several times with the same result; nevertheless the greater portion of the liquid eventually distilled between $220^{\circ}$ and $240^{\circ}$. That fraction which boiled between $175^{\circ}$ and $180^{\circ}$ gave all the qualitative reactions for cymene; on oxidation, it yielded terephthalic acid.

Like the other terpenes of the formula $\mathrm{C}_{10} \mathrm{H}_{16}$, the lowerboiling terpene from sage-oil appears to be readily converted into a dibromide, which is decomposed by the action of heat, with the formation of cymene. This decomposition does not, 
however, take place with so great facility as has been noticed in the case of other terpenes of higher boiling-points *.

10. About 25 cubic centims. of the terpene boiling at $157^{\circ}$ was subjected to the action of two litres of boiling chromic liquor, containing 10 per cent. of potassium dichromate, and sulphuric acid sufficient to saturate the bases present. After 37 hours the boiling was stopped, and the small quantity of solid matter which had been produced was collected, washed with hot water, dissolved in boiling ammonia, and reprecipitated by hydrochloric acid. It gave the reactions of terephthalic acid. The liquid, when distilled, showed the reactions for acetic acid.

The residue, after polymerizing the terpene with sulphuric acid in the manner described in paragraph 8 , and distilling in steam, was boiled for some days in ehromic liquor. No solid oxidation-product was obtained.

Wright $\dagger$ has shown that the terpene from orange-peel oil, boiling at $178^{\circ}$, yields no cymone when treated with strong sulphuric acid and distilled in steam, nor does it yield a trace of terephthalic acid on oxidation. The same chemist $\ddagger$ has also shown that oil of turpentine yields cymene by treatment with sulphuric acid \&c. According to some chemists terephthalic acid is one of the products of the oxidation of oil of turpentine; according to others this acid is not produced on oxidizing that oil. The fact that, when cymene had been removed from the liquid portion of sage-oil boiling at $157^{\circ}$, the residue yielded no terephthalic acid on oxidation, although the original liquid (before treatment with sulphuric acid \&c.) did yield this acid, seems to point to the cymene which was present as the source whence the terephthalic acid was derived.

The varying results obtained in the oxidation of oil of turpentine were probably due to the varying composition of the specimens employed; when free from cymene, this oil appears to yield no trace of terephthalic acid on oxidation $\$$.

11. That portion of the oil which, after treatment with sodium and distillation, boiled from $166^{\circ}$ to $168^{\circ}$, was fractionated until the greater part boiled constantly from $167^{\circ}$ to $168^{\circ}$ (thermometer surrounded with vapour; barometer 760 millims.). The liquid so obtained had a somewhat more pronounced odour of sage than the fraction which boiled at $157^{\circ}$; it was perfectly colourless.

* See Wright, "On Isomeric Terpenes," Chem. Soc. Journ. [2] xi. p. 694.

† Chem. Soc. Journ. [2] xi. p. 552.

$\ddagger$ Loc. cit.

\$ See W. Carleton Williams, Ber. deut. Chem. Ges. v. 1094. 
The following are the results of a vapour-density determination of this liquid:-

Height of barometer $=758$ millims.

Temperature of air $=18^{\circ}$.

Height of mercury column in barometer-tube $=511$ millims.

Temperature of vapour $=185^{\circ}$.

Tension of mercury vapour at $185^{\circ}=12$ millims.

Weight of mercury required to occupy space formerly occupied by vapour $=874 \cdot 7$ grams.

Temperature of mercury $=20^{\circ}$.

Hence, volume of vapour $=64 \cdot 61$ cubic centims.

Weight of liquid $=0.0804$ gram.

Weight of volume of hydrogen equal to volume of vapour under same conditions of temperature and pressure $=$ 0.001129 gram.

$$
\text { Hence } \frac{M}{2}=\frac{\cdot 0804}{.001129}=71 \cdot 2 . \quad \text { Calculated }=68 \text {. }
$$

Two experiments, in addition to that the results of which are detailed, were carried out; but in each a small quantity of air found its way into the barometer-tube ; the results were therefore too low. In every case a small quantity of brown resinous matter remained in the small bottle unvolatilized; hence it appears either that the terpene contained a small quantity of a substance boiling very considerably above $185^{\circ}$, or that the action of such an amount of heat as is represented by this temperature exerted a decomposing (polymerizing?) action upon the terpene. The presence of 4 per cent. of a terpene of the formula $\mathrm{C}_{15} \mathrm{H}_{24}$, supposing this to remain completely unvolatilized, would bring the observed vapour-density to $68 \cdot 3$, which is almost identical with the calculated number.

12. The specific gravity of the terpene boiling at $167^{\circ}$ to $168^{\circ}$ was 0.8866 at $15^{\circ}$.

We are again indebted to the kindness of Dr. Gladstone for determinations of the refractive indices of this terpene.

$$
\mu \mathrm{A}=1 \cdot 4588, \mu \mathrm{D}=1 \cdot 4646, \mu \mathrm{H}=1 \cdot 4830 \text {, at } 24^{\circ} \cdot 5 \text {. }
$$

Hence, specific refractive energy $=0.0522$, and

$$
\text { Refraction equivalent }=71 \cdot 0 \text {. }
$$

13. Dr. Tilden has been so good as to examine the action of nitrosyl chloride upon this terpene. He says, "I could get no so id products from this liquid. The action of the gas caused effervescence immediately; and this is always $a$ bad sign. I suspect this to be a mixture containing a hydrocarbon of the $\mathrm{C}_{15} \mathrm{H}_{24}$ type. I never got any solid contpounds 


\section{Messrs. M. M. Pattison Muir and S. Sugiura on}

from these." The specific rotatory power of the terpene boiling at $167^{\circ}$ to $168^{\circ}$ is $[\alpha]_{\mathbf{D}}=-19 \cdot 9$.

14. The results of the vapour-density determination detailed in paragraph 11 led us to look on the presence of a small quantity of a higher-boiling liquid in this terpene $\left(\mathrm{C}_{15} \mathrm{H}_{24}\right.$ ?) as probable. It might be supposed that the liquid boiling at $167^{\circ}$ to $168^{\circ}$ is really a mixture of the terpene of lower boiling-point with about 4 per cent. of a terpene of the type $\mathrm{C}_{15} \mathrm{H}_{24}$ (paragraph 11). Such a mixture-assuming the $\mathrm{C}_{15} \mathrm{H}_{24}$ terpene to bave a specific gravity of 0.915 , which is about the mean of the densities of terpenes of this formula as determined by Gladstone, and assuming that no condensation of volume occurred through mixing the two liquidswould have a specific gravity of about 0.865 at $15^{\circ}$; but tho liquid boiling at $167^{\circ}$ to $168^{\circ}$ has a specific gravity of 0.8866 at $15^{\circ}$. The assumption that this liquid is a mixturo of the $157^{\circ}$ terpene and such an amount of a $\mathrm{C}_{15} \mathrm{H}_{24}$ terpene as would be in keeping with the result of the vapour-density determination, is therefore not borne out by the actual specific gravity of the liquid. We are rather inclined to believe that sage-oil contains two terpenes of the formula $\mathrm{C}_{10} \mathrm{H}_{16}$, differing in physical properties, and perhaps a small quantity of a terpene of higher molecular weight.

The physical as well as the chemical properties of the terpene boiling at $157^{\circ}$ leave little doubt of the identity of this compound with terebenthene, the terpene obtained from French oil of turpentine. The terpene boiling at $167^{\circ}$ to $168^{\circ}$ we cannot regard as perfectly pure. In a letter to one of us, Dr. Gladstono says, "The lighter terpene is practically identical with that from turpentine in refraction and dispersion, as well as in boiling-point and specific gravity. The heavier one, with the higher boiling-point, has a lower refractive energy than any terpene I have examined. Is it pure?"

Investigations carried out on larger quantities of oil can alone enable us to make positive statements regarding the composition of the higher terpene.

15. Treatment of the terpene boiling at $167^{\circ}$ to $168^{\circ}$ with strong sulphuric acid, and distillation of the product in steam, in the manner described in paragraph 8 , resulted in the production of about 8 per cent. of a liquid which gave the reactions for cymene, and on oxidation with chromic liquor yielded terephthalic and acetic acids. The polymerized residue yielded no solid oxidation-product on treatment with chromic liquor.

The terpene itself when oxidized, yielded a considerably larger quantity of terephthalic acid than was obtained from the $157^{\circ}$ terpene. 
A portion of this terpene, when treated with bromine, as described in paragraph 9, reacted in a manner very similar to that already cletailed in the case of the terpene of lower boiling-point; only, on distilling the brominated liquid, it was very readily and almost entirely split up into hydrobromic acid and cymene.

16. That portion of the original oil which, upon fractionation, boiled between $198^{\circ}$ and $203^{\circ}$, was a nearly colourless heavy liquid, having a very strong odour of sage. It did not become sensibly darker on exposure to the air.

For this liquid, which represents the oxidized liquid constituent of sage-oil, we propose the name of salviol. We have analyzed salviol, and have also made a determination of its vapour-density.

I. 0.1664 grm. gave $0.48 \mathrm{grm} . \mathrm{CO}_{2}$ and $0.162 \mathrm{grm} . \mathrm{H}_{2} \mathrm{O}$. II. $0.130 " 0.374, \mathrm{CO}_{2} " 0.124 " \mathrm{H}_{2} \mathrm{O}$.

Calculated for $\mathrm{C}_{10} \mathrm{H}_{16} \mathrm{O}$.

$\begin{array}{lrrr}\text { Carbon ......... } & \text { I. } & \text { II. } & \text { Mean. } \\ \text { Hydrogen ..... } 10 \cdot 53 & 78 \cdot 69 & 78 \cdot 46 & 78 \cdot 57 \\ \text { Oxygen ........ 10.53 (by diff:) } 10 \cdot 50 & 10 \cdot 81 & 10 \cdot 59 & 10 \cdot 70 \\ & & 10.95 & 10 \cdot 73\end{array}$

Vapour-density determination.

Height of barometer $=755$ millims.

Temperature of air $=17^{\circ}$.

Height of mercury column in barometer-tube $=492$ millims. Temperature of vapour $=185^{\circ}$.

Tension of mercury vapour at $185^{\circ}=12$ millims.

Weight of mercury required to occupy space formerly occupied by vapour $=788 \cdot 1$ grams.

Temperature of mercury $=17^{\circ}$.

Hence, volume of vapour $=58 \cdot 16$ cubic centims.

Weight of liquid $=0.0786 \mathrm{gram}$.

Weight of volume of bydrogen equal to volume of vapour under same conditions of temperature and pressure $=$ 0.00107 gram.

$$
\text { Hence } \frac{M}{2}=\frac{\cdot 0786}{.00107}=73 \cdot 46 \text {. Calculated }=76 \text {. }
$$

A small quantity of resinous matter remained in the littlo bottle at the conclusion of the experiment. The weight of this non-volatile residue was found to be 0.0014 gram. The number given above as representing the weight of liquid taken is the difference between the actual amount weighed out and the weight of the non-volatile residue. 


\section{Messrs. M. M. Pattison Muir and S. Sugiura on}

It would appear that the salviol examined was not perfectly pure, or that this substance is decomposed in some way at the temperature to which it was raised, with production of resinous matter. There can, however, be little doubt that the formula $\mathrm{C}_{10} \mathrm{H}_{16} \mathrm{O}$ really represents not only the quantitative composition, but also the molecular weight of salviol.

From the smallness of the quantity of salviol at our disposal we have not been able to carry out further experiments upon this substance.

17. The solid which separated from the higher-boiling portions, chiefly from the fractions boiling from $190^{\circ}$ to $220^{\circ}$, has been partially examined by us.

\section{Analysis.}

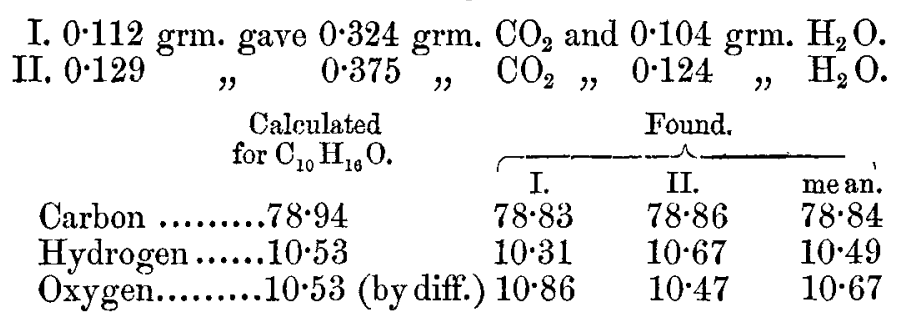

We have not made a vapour-density determination, inasmuch as the results of analysis leave little doubt as to the correctness of the formula $\mathrm{C}_{10} \mathrm{H}_{16} \mathrm{O}$, and the boiling-point prevents the supposition that the molecular weight is represented by a multiple of this formula.

The specific gravity of sage-camphor is greater than that of common camphor, and less than that of borneol. We do not consider the actual numbers obtained by us yet sufficiently trustworthy for publication.

After several sublimations sage-camphor melts at $184^{\circ}$ to $186^{\circ}$, and boils at $210^{\circ}$.

This substance crystallizes in monoclinic prisms, $\infty \mathrm{P},-m \mathrm{P}$; the crystals are generally rounded off on the prism-edges.

An alcoholic solution of sage-camphor is without action upon the polarized ray.

The appearance, smell, and taste of this camphor closely resemble those of the common variety; sage-camphor, however, has a peculiar sage-like odour, which ordinary camphor has not. Sage-camphor is soluble to a very slight extent in water; it swims upon the surface of water, and exhibits the peculiar rotatory movements of camphor. It is soluble in alcohol (from which solution water precipitates it in the form of white flakes), in chloroform, and in ether. Nitric acid 
dissolves sage-camphor with the evolution of small quantities of lower oxides of nitrogen (see paragraph 20). Sulphuric acid dissolves it with difficulty, and hydrochloric acid only after continued boiling.

18. A quantity of sage-camphor was dissolved in chloroform; an equal quantity of bromine was gradually added, the vessel being kept well cooled. Reddish-coloured crystals were almost immediately deposited. The whole was allowed to stand over sulphuric acid in vacuo for 12 hours: when the vessel was brought into the ordinary atmosphere the crystals very quickly melted, and hydrobromic acid was evolved in considerable quantity. On standing for several days over sulphuric acid in vacuo, crystals were again formed. On distilling the red liquid very large quantities of hydrobromic acid were evolved, a camphor-like solid was deposited, and a considerable portion of the liquid was resinized. The solid camphor-like substance, after several sublimations, melted at $160^{\circ}$ to $163^{\circ}$. A similar substance, having the same meltingpoint, was prepared by treating sage-camphor directly with bromine, washing with caustic soda, and subliming. The melting-point of the crystals increased after each sublimation, until the maximum, $160^{\circ}$ to $163^{\circ}$, was attained. During the earlier sublimations hydrobromic acid was evolved.

19. When sage-camphor was distilled in contact with phosphorus pentasulphide, the greater part of the material underwent resination, but a small quantity of liquid was obtained, which, after washing with soda, drying, and fractionating, gave the reactions of cymene; on oxidation with chromic liquor terephthalic acid was produced.

20. A few grams of sage-camphor was dissolved in about 10 parts of concentrated nitric acid, the liquid was boiled for 30 hours or so, the acid was distilled off ; the residual semiresinous matter was dissolved in hot water; the solution was boiled down and set aside. A small quantity of a colourless, indistinetly crystalline body was obtained. This substance melted at $172^{\circ}$ to $176^{\circ}$. The quantity at our disposal was too small, and not sufficiently pure, to allow of accurate analyses being made; the numbers which we did obtain agreed as closely as could be expected with those required by the formula for camphoric acid $-\mathrm{C}_{10} \mathrm{H}_{16} \mathrm{O}_{4}$.

21. Sage-camphor is almost certainly an isomer of common camphor; its melting-point, boiling-point, and other physical properties, however, as also the difference of its behaviour towards bromine, prevent us from believing that it is identical with common camphor.

22. Our investigations are not sufficiently complete to 
allow us to enter into theoretical discussions concerning the structural formula of camphor and the substances related to it; nor can wo venture to make any generalizations concerning the members of the terpeno group. Both of these subjects are of much interest. We purpose to prepare much larger quantities of the terpenes, salviol, and sage-camphor, and to determine the physical and chemical properties of these bodies, combining this investigation with a research into the constitution of the camphors in general.

We take this opportunity of again returning our best thanks to Drs. Gladstone and Tilden for their kindness in examring the optical and other properties of the two sagetorpenes.

XLVII. On the Lover Limit of the Prismatic Spectrum, with especial reference to some Observations of Sir John Herschel. By Lord Rayleigh, F.R.S.*

A LL theoretical investigations into the laws of dispersion A have led to the conclusion that, as the wave-length of light increases, the refractive index for a given substance approaches a finito limit, below which it cannot pass. According to Cauchy, the refractivo index $(\mu)$ can be expressed approximately as the sum of two terms; of which the first is constant and coincident with the limiting value just spoken of, while the second varies inversely as the square of the wave-length ( $\lambda$ ). This law, which may be expressed $\mu=A+B \lambda^{-2}$, agrees very well with observation over the less-refrangible part of the spectrum, and may fairly be extended to the ultra-red rays ; so that, apart from all theory, there is good reason for thinking that $\mu$ cannot fall below a certain value, however great the wave-length may be.

In estimating the place of the limit on any particular map of the spectrum, we must bear in mind that in ordinary prismatic spectra equal distances do not correspond to equal differences of $\mu$. The prismatic spectrum as seen at one view through a prism of considerable angle depends, not only upon the material and angle of the prism, but also upon the actual position in which the prism is placed. Thus different spectra are obtained according to the ray selected for minimum deviation : if the green ray pass with minimum deviation, the deviations of the extreme rays of the spectrum are greater than if the prism were set specially for them, and thus the red end of the spectrum is unduly compressed and the blue end is un-

* Communicated by the Author, having been read in substance before the British Association at Plymouth, August 1877. 